\title{
O VALOR HISTÓRICO-AMBIENTAL INSERIDO NA PRAÇA 5 DE SETEMBRO CONHECIDA COMO PRACA DA SAUDADE EM MANAUS: DA BELLE ÉPOQUE À MODERNIDADE
}

Silvana Cruz ${ }^{1}$

Rosenir Lira ${ }^{2}$

Aurilene Carvalho ${ }^{3}$

Vera Gil de Oliveira ${ }^{4}$

RESUMO: Este ensaio apresenta a Praça 5 de setembro, conhecida popularmente como Praça da Saudade em Manaus, cujo monumento retrata a Elevação do Amazonas à Categoria de Província, enriquecida com a estátua de bronze do $1^{\circ}$ Presidente da Província do Amazonas, João Batista Figueiredo Tenreiro Aranha.O trabalho, faz uma abordagem histórico-ambiental da cidade de Manaus, enfatizando o uso da praça, como local apropriado para lazer,contemplação e discussão política. É uma tentativa de através do resgate histórico-ambiental, refletir a importância da memória e da identidade da cidade. Recomenda a inserção de estratégias metodológicas educacionais para se praticar a educação ambiental, através de políticas públicas voltadas a esta temática. Conclama a população para conhecer e valorizar este espaço cultural destinado ao povo.

\footnotetext{
${ }^{1}$ Mestra em Educação, Pedagoga da UFAM. silvanaheloisa@ufam.edu.br

2 Doutor em Educação, Professor da Faculdade de Educação - UFAM. rosenirlira@ufam.edu.br

${ }^{3}$ Professora do Ensino Básico. Aurilene19@hotmail.com

${ }^{4}$ Mestranda em Engenharia de Produção, UFAM. vitoria@ufam.edu.br
} 
Palavras-chave: praça da saudade, Manaus, educação ambiental.

\section{INTRODUÇÃO}

A praça 5 de setembro, conhecida popularmente como "PRAÇA DA SAUDADE", foi inaugurada em 1865 e inicialmente era conhecida como Largo da Saudade. Seus limites davam-se com o Instituto de Educação do Amazonas (IEA) e o Cemitério São José, onde hoje se encontra a sede do Rio Negro Clube.Passou a denominação de praça em 1897, mas só em 1962 foram construídos os jardins e passeios. Seu projeto original foi modificado em 1938, em seus canteiros foram incluídos vegetação exótica. Já em 1963 foram colocados estátuas de bronze que representam os homens primitivo e moderno, época em que foram retirados as pérgolas laterais.

Atualmente a praça possui aproximadamente 12,6 mil metros quadrados, limita-se com as ruas Epaminondas, Ramos Ferreira, Ferreira Pena e Simão Bolivar, está localizada em plena área central de Manaus.

Registra-se em documentos que a área ocupada pela praça era bem mais ampla, à época do governo Eduardo Ribeiro, uma vez que esta ia desde o antigo cemitério chamado de São José, localizado onde é atualmente a sede do Rio Negro Clube até o Instituto de Educação do Amazonas.

É possível dizer que o nome de Largo ou Praça da Saudade foi batizado pelo povo por estar localizado bem em frente ao cemitério de São Jose, que também emprestava nome ao bairro, sendo aberta ao público em 1865, bem depois da construção do cemitério. 
Segundo o historiador Mário Ypiranga Monteiro, o nome da praça pode ter originado devido a presença de um espanhol de sobrenome "saudade" ou de um negro que viveu por volta de 1837, morador da área vizinha à praça, de nome José Pedro Saudade, Ainda segundo Monteiro, o negro, seria um escravo de forro, devido aos bens que possuía.

Já o nome oficial da Praça 5 de setembro, foi constituído em homenagem a data da Elevação do Amazonas á categoria de província, uma justa homenagem a Tenreiro Aranha que lutou pela emancipação do Amazonas.

Mendonça ( 2000:543) ao se reportar sobre a Elevação do Amazonas à Categoria de Província,e seu reconhecimento a figura de João Batista de Figueiredo Tenreiro Aranha, diz:

Este foi o grande momento de um povo, glorioso e forte, que tornou positivo os princípios essenciais da vocação histórica do Amazonas, para a obra que estamos construindo com idealismo e patriotismo.

Para nós, como para o Amazonas, não há, depois de sua elevação à categoria de Província, outro acontecimento mais culminante - ele nos descortina a armadura homérica dos seringueiros, juteiros, piaçabeiros, castanheiros, madeireiros, garimpeiros, vaqueiros, na luta de todas as horas e todos os instantes, pelo engrandecimento do vale maravilhoso. Ainda sobre Aranha, ressalta [...] Para esse homem de atitude colossal e de inteligência superior, o Amazonas, num sentimento profundo, comum aos corações agradecidos, que se eleva até a grandeza do Infinito,ergueu-se à Praça da Saudade, um monumento grandioso dignificante às futuras gerações de minha terra. (556)

\section{PRAÇA DA SAUDADE COMO LOCAL DE CONTEMPLAÇÃO E QUALIDADE DE VIDA}

A Praça da Saudade é um espaço público de lazer, de contemplação e harmonia, onde crianças, jovens, adultos, moradores da cidade e turistas vão apreciar a beleza histórica e paisagística, vemos elementos de cunho arquitetônico misturados a rica vegetação amazônica, em perfeita harmonia, uma beleza que faz bem aos olhos de quem aprecia a beleza da natureza criada e aperfeiçoada pelas mãos do homem da terra. 
O poeta Thiago de Mello ( $1984: 88 / 89$ ) ao falar sobre a beleza da arquitetura de Manaus, reconhece especificamente a autêntica e legítima arquitetura amazonense, nascida da sabedoria e da cultura popular. Confirma, o que as pessoas já sabem:

As grandes residências e edifícios públicos erguidos em Manaus a partir do início do século, tanto os casarões ajanelados com pedra de cantaria como as casinhas de alvenaria de rés de chão, de portas com bandeira envidraçada e colorida, todas eram (ou ainda são, as que não foram derrubadas) de bom fino risco europeu.

Historicamente a praça como local público, é concebido na maioria das vezes como lugar de criação, difusão e intercâmbio de culturas, também é possível perceber significados diferenciados, vejamos dois exemplos clássicos de significados de praça na cultura grega e na romana.

Na literatura, observamos o modelo e o significado de praça para os gregos clássicos. Ágora era um modelo de praça estilo grego inserido aspecto simbólico bastante importante na cultura do povo grego, também utilizada para se praticar a democracia direta, sendo o lugar por excelência da discussão e do debate de idéias entre cidadãos. A ágora se delimitava por mercados e demais edifícios, dando possibilidades para ver a acrópole, a morada dos deuses na mitologia grega. Nesses espaços de prática da democracia emergente praticava-se o governo do povo, onde o conhecimento popular podia ser ouvido por todos, inclusive os sábios.

As praças romanas conhecidas como o fórum romano representava em si mesmo a monumentalidade do Estado, posto que o indivíduo que por ele passasse estava espacialmente subordinado aos enormes prédios públicos que o configuravam. Era diferente da ágora, pois o espaço da discussão não era a praça pública, aberta, mas o espaço fechado dos edifícios, nos quais a penetração era mais restrita. 
É possível dizer que até meados do Século XVIII, o projeto de praças estava normalmente restrito ao tratamento paisagístico de grandes palácios, nem sempre inseridos no contexto urbano.

Os espaços livres existentes nas cidades configuravam-se de forma não ordenada, em geral devido à existência de mercados populares ou às entradas de igrejas e catedrais.

Percebemos o grau de importância de um espaço público, no caso aqui tratado, a praça inserida ao modelo democrático brasileiro, quando bem utilizado pelo povo pode ser um rico espaço de criação e recriação de um modelo de sociedade.

A Praça da Saudade pode ser utilizada por seus freqüentadores como uma possibilidade de espaço para se praticar a democracia e se ter qualidade de vida.

Devido o caráter amplo e complexo de qualidade de vida que abrange significados objetivos e subjetivos, nas sociedades contemporâneas objetivando propostas sociais para a construção conjugada de cidadania, justiça social e sustentabilidade ambiental.

A esse respeito Herculano ( 2000: 237 apud Lima 2002:133/134), propõe um conceito amplo em que:

\begin{abstract}
"qualidade de vida" seja definida como a soma das condições econômicas, ambientais, científico-culturais e políticas coletivamente construídas e postas à disposição dos indivíduos para que estes possam realizar suas potencialidades: inclui a acessibilidade à produção e ao consumo, aos meios para produzir cultura, ciência e arte, bem como pressupõe a existência de mecanismos de comunicação, de informação, de participação e de influência nos destinos coletivos, através da gestão territorial que assegure água e ar limpos, higidez ambiental, equipamentos coletivos urbanos, alimentos saudáveis e a disponibilidade de espaços naturais amenos urbanos, bem como da preservação de ecossistemas naturais.
\end{abstract}

Até pouco tempo, a referida praça encontrava-se em reforma, e sua reforma deu-se por conta de um convênio firmado entre Prefeitura de Manaus e a SUFRAMA (Superintendência da Zona Franca de Manaus). 
Em 2008, a Prefeitura de Manaus e a SUFRAMA assinaram convênio pela revitalização da Praça da Saudade, no valor de 2 milhões e 530 mil para obras de revitalização da histórica Praça da Saudade, de acordo com projeto vai recuperar o traçado original da praça com restauração do monumento, mobiliário, casas do entorno e a recuperação de calçadas, meios-fios e sarjetas. A Prefeitura vai instalar 60 bancos, quatro playgrounds e arborização por meios de caramanchões para proteção de sol.

Vale registrar a observação feita pelo então prefeito da época, Serafim Corrêa, que diz:

\begin{abstract}
A Praça da Saudade é uma das mais importantes de Manaus. Historicamente temos o monumento de Elevação do Amazonas à categoria de Província com a estátua do primeiro presidente, Tenreiro Aranha. Devemos resgatar nossos monumentos junto com a história e difundi-los para novas gerações. Este é um compromisso da Prefeitura e para o qual convoco a população a participar desse esforço que tem uma importância muito grande na motivação da auto estima de todos nós que amamos Manaus.
\end{abstract}

Ressalta-se que a iniciativa de revitalização da Praça da Saudade é de autoria do senador Jeferson Péres, presente à solenidade, hoje já falecido. O senador sempre defendeu a revitalização da praça onde funcionava a Secretaria de Justiça do Estado (Sejusc) e por ele considerado "um monstrengo". O prédio foi demolido em outubro de 2007.

Atualmente, a praça da Saudade, foi reinaugurada pelo prefeito Amazonino Mendes, totalmente recuperada, com infraestrutura urbana, sem perder o charme de Belle Époque que a consagrou como a Paris na América. Recebeu um belo sistema paisagístico,combinado com os jardins cobertos de plantas coloridas. Está totalmente iluminada, foi também contemplada com um sistema de acesso à Internet Wireless permanente instalado no local.

No paisagismo encontram-se plantas: mini-ixórias, alamandas, durantos, palmeiras, açaizeiros, bougaivilles, oitizeiros e pau-pretinho. Em seus jardins há plantas ornamentais 
com uma diversidade de espécies, remonta aos jardins europeus que enfeitavam Manaus no período áureo da borracha.

O atual prefeito de Manaus Amazonino Mendes, ao entregar a obra, disse que "a praça é também um resgate de parte de sua juventude. Os bougainvilles, flores conhecidas também como primaveras, eram a marca registrada da praça e agora as novas gerações vão poder contemplar esse espaço bucólico que é a cara de Manaus no período da Belle Époque".

\section{CONSIDERAÇÕES FINAIS}

Pode-se utilizar a praça como espaço público para se trabalhar a prática da educação ambiental utilizando a metodologia interdisciplinar através de uma seleção de temas a serem trabalhados como: as estátuas de bronze, a flora, as plantas ornamentais, a arquitetura, os bancos de madeira, a calçada, o piso etc. Feito isto, as políticas públicas de educação ambiental do município devem oferecer estratégias de entretenimentos e lazer via peças teatrais, músicas e danças, cantigas de roda,entre outros para promover a conscientização ambiental do usuário da praça, bem como chamar a comunidade para participar desse processo de resgate histórico-ambiental da cidade de Manaus.

As praças em Manaus são uma forma de lazer alternativa para seus habitantes e de fácil acesso, principalmente à população menos favorecida financeiramente, tendo também outros valores como a valorização histórica e cultural da população, assim como a importância da preservação do meio ambiente para nossas vidas. Visto que o meio ambiente segundo Reigota:

Um lugar determinado e/ou percebido onde estão em relações dinâmicas e em constante interação os aspectos naturais e sociais. Essas relações acarretam processos de criação 
cultural e tecnológica e processos históricos e políticos de transformação da natureza e da sociedade. (1994)

Partindo desse conceito pode-se evidenciar a importância que a reconstrução dessa praça exerce sobre o meio ambiente e a representação social dos cidadãos que a freqüentam, haja vista que as representações sociais são construídas ao longo dos tempos conforme o contexto no qual o individuo está inserido.

\section{REFERÊNCIAS}

LIMA, Gustavo Ferreira da Costa. Crise ambiental, educação e cidadania: os desafios da sustentabilidade emancipatória. In: BAETA, Anna Maria Bianchini et al. Educação ambiental: repensando o espaço da cidadania. São Paulo: Cortez, 2002.

MELLO, Thiago de. Manaus, amor e memória. Rio de Janeiro: Philobiblion,1984.

REIGOTA, Marcos. O que é Educação Ambiental. Brasiliense. São Paulo,1994.

REVISTA AMAZON VIEW ,Ano XV, Edição 95, Manaus, 2010.

SKYSCRAPER CITY - Disponível em http://

WWW.skyscrapercity.com/showthread.php?=577082 Acesso em 16/08/2010.

SOUZA, João Mendonça de. O Grande Amazonas: mitologia, história e sociologia. $2^{\underline{a}}$ ed. rev. Aum. Manaus, 2000. 